\title{
Influence of Fluid Replacement on Short-Term Recovery and Subsequent Exercise Performance 液體補充對短期恢復及隨後運動時能力之影響
}

\author{
Stephen H.S. Wong \\ Department of Sports Science \& Physical Education \\ The Chinese University of Hong Kong, HONG KONG
}

王香生

香港中文大學體育運動科學系

\begin{abstract}
Rapid fluid replacement and replenishment of muscle glycogen after prolonged exercise are vital for optimal substrate provision, cardiovascular function, and thermoregulation during subsequent bouts of vigorous exercise on the same day. This paper reviews recent work relating to the effects of rehydration with carbohydrate-electrolyte solutions during a short-term recovery period on hydration status, physiological responses, and subsequent endurance capacity. Issues investigated and discussed were drinking patterns, amount of carbohydrate $(\mathrm{CHO})$ consumed, and the volume of fluid ingested. The data are presented as a series of summaries of experiments, followed by a discussion of the implications. The main findings of the studies reported suggest that in order to achieve euhydration during short-term recovery, a volume of fluid substantially larger than that lost must be ingested. The provision of additional CHO would be expected to restore the body's $\mathrm{CHO}$ stores to a greater extent than a smaller amount of $\mathrm{CHO}$ during the recovery and, thereby, improve the subsequent endurance capacity. However, this was not the case. It appears that the ingestion of large amounts of $\mathrm{CHO}$, during a short recovery period, resulted in disturbances in fat and $\mathrm{CHO}$ metabolism which prevented an improvement in endurance capacity during subsequent exercise, after consumption of the additional $\mathrm{CHO}$.
\end{abstract}

\section{摘要}

運動後迅速補充水份及恢復肌肉內的糖元對同日要進行的激烈運動十分重要, 因爲能量代謝、心肺功能及體溫調節也以此 鹞基檚。本文主要綜述最近有關此課題之研究, 旨在探討在含有碳水化合物及電解質之飲品影響下, 體內水份所作出之調節、 各項生理變化及恢復後之運動能力。研究結果顯示, 若要在短時間之恢復期內重新達至水份本衡, 人體有需要攝取比在運動時 所失去之水份爲多之液體。在此短暫恢復期間, 若攝取大量的碳水化合物將會引致能量代謝出現不正常的反應, 並會影響隨後 的運動能力。

\section{Introduction}

Nutrition as one of the most important factors influencing physical performance has attracted considerable attention from sports scientists, athletes, and coaches over the last 50 years. Despite the wealth of published information dealing with "proper nutrition" and the advocacy of a healthy, well-balanced diet, numerous athletes still believe that special foods or dietary supplements are necessary for optimal performance. However, it is now firmly established that carbohydrate (CHO) is the most essential nutrient for prolonged, intense training and successful athletic performance (Costill, 1988; Williams, 1993). Yet, its stores within the body are relatively small.
The classical studies of Christensen and Hansen (1939a, 1939b) clearly demonstrated the importance of $\mathrm{CHO}$ availability during prolonged exercise and the potential influence of dietary $\mathrm{CHO}$ on endurance exercise performance. After the introduction of the percutaneous muscle biopsy technique, it became clear that at exercise intensities higher than $70 \% \mathrm{VO}_{2}$ max, the concentration of muscle glycogen is a determinant of endurance exercise capacity (Bergstrom \& Hultman, 1967; Bergstrom et al., 1967; Hermansen et al., 1967). Although the depletion of the body's CHO reserves is the primary cause of fatigue in prolonged exhaustive exercise, other factors concurrently exist to limit human performance. One of those physiological perturbations that cause early fatigue is the failure of the body to maintain 
fluid balance which, in turn, affects the efficiency of thermoregulation during exercise (Coyle \& Montain, 1992; Montain et al., 1998). The rise in body temperature that normally accompanies exercise stimulates an increase in blood flow to the skin and the onset of sweating. A balanced hydration status is, therefore, a good protection of these thermoregulatory responses, whereas even a slight amount of dehydration results in measurable declines in cardiovascular and thermoregulatory function (Costill \& Sparks, 1973; Nadel et al., 1980; Heaps et al., 1994; Montain et al., 1998).

Mild to severe dehydration commonly occurs among athletes, even when fluid is readily available (Carter \& Gisolfi, 1989; Gonzalez-Alonzo et al., 1992; Nielsen et al., 1986; Noakes et al., 1988). This involuntary dehydration (Greenleaf \& Sargent, $1965)$ not only compromises physiological function, but also impairs exercise performance and increases the risk of heat intolerance and illness. A recent study has shown that a body weight loss of only $1.8 \%$ impaired exercise time to exhaustion during highintensity cycling (Walsh et al., 1994). In view of the importance of substrate availability and fluid balance before or during exercise, it is not surprising to find that numerous studies have been undertaken in these areas over the past decades. The research findings result in a comprehensive understanding of the $\mathrm{CHO}$ utilisation during exercise and the physiological consequences of dehydration and, more recently, of the physiological and performance benefits of euhydration (Below et al., 1995; Montain \& Coyle, 1992a, 1992b; Montain et al., 1998). Since reduction, or depletion, of the body's CHO stores and dehydration are the inevitable results of prolonged, heavy exercise, it is logical to assume that the two main goals of the recovery strategy of athletes, following prolonged exercise, are to achieve complete rehydration and replenish their muscle glycogen stores rapidly. It is particularly true for those individuals involved in activities that elicit large sweat losses, and in which more than one bout of exercise may be completed in a single day.

Rehydration following exercise involves the administration of dilute $\mathrm{CHO}$-electrolyte (CHO-E) solutions which can be rapidly emptied from the gastrointestinal (GI) tract. CHO-E solutions can serve the twin aims of providing a source of $\mathrm{CHO}$ to replenish the body's limited stores and supply water and electrolytes to achieve rehydration after exercise. Dehydration does not delay muscle glycogen resynthesis (Neufer et al., 1991), but it may be responsible for an inability to recover completely from prolonged exercise. In a hot environment, rehydration is even more important because the consequences of dehydration are potentially life threatening.

Whilst the benefits and the physiological responses of fluid replacement with $\mathrm{CHO}$ before, and during, exercise have been extensively studied by scientists interested in sports nutrition, not much research has been undertaken to investigate the effects of rapid restoration of $\mathrm{CHO}$ reserves and rehydration during the post-exercise recovery period, let alone the question of the nutritional strategies on subsequent exercise performance. The majority of those studies investigating the post-exercise recovery period have focused on the influences of $\mathrm{CHO}$ ingestion on muscle glycogen resynthesis and the optimal composition of rehydration fluids. Yet, few have examined the effects of the resulting glycogen and hydration levels on the return of functional capacity. It is generally assumed that nutritional strategies stimulating the high rates of muscle glycogen resynthesis and level of rehydration after exercise will result in a greater restoration of exercise capacity than strategies resulting in slower rates of glycogen resynthesis and rehydration. Thus, the following studies reported were to examine the influence of rehydration with CHO-E solutions during a short-term recovery period on hydration status, physiological responses, and subsequent running capacity. The results of these studies are presented in a sequence that progresses from a consideration of the influence of the drinking patterns, to the effects of fluid volume on achieving euhydration during shortterm recovery.

\section{General Methods of Studies}

A standardised "recovery" protocol developed by Fallowfield et al. (1995) was used throughout the studies reported in order to investigate the influence of rehydration on subsequent endurance capacity. This experimental protocol basically involved a $90 \mathrm{~min}$ constant pace run at $70 \% \mathrm{VO}_{2} \max (\mathrm{T} 1)$, followed by a $4 \mathrm{~h}$ rehydration-recovery period (REC), and a subsequent open-ended endurance run to exhaustion at the same exercise intensity (T2) (Figure 1). The REC was selected for comparison with similar periods in previous studies that assessed the effects of various fluid replacement regimens on rehydration and subsequent exercise performance (Lambert et al., 1992; Ivy et al., 1988b; Keizer et al., 1987; Nielsen et al., 1986; Fallowfield et al., 1995; Fallowfield $\&$ Williams, 1997). The trials were separated by at least 7 days and the order of these experiments was randomised and administered in a double-blind, cross-over design. The purposes of the T1 (i.e. $90 \mathrm{~min}$ run at $70 \% \mathrm{VO}_{2} \max$ ) were twofold: firstly, to reduce muscle glycogen concentration in both fibre types (Ivy et al., 1988a; Tsintzas et al., 1995, 1996), secondly, to induce significant body fluid loss ( $>2.0 \%$ body mass) which, if not replaced, impairs subsequent exercise performance (Armstrong et al., 1985).

\section{Effects of Drinking Patterns on Recovery}

It has been shown that short-term recovery from exhausting exercise is enhanced, and subsequent endurance capacity is improved, 
by ingesting a CHO-E solution immediately after exercise (Fallowfield et al., 1995). However, it is unclear how a particular drinking pattern, during such short-term recovery, will in turn influence the level of rehydration and subsequent endurance capacity. Thus, a study was undertaken to investigate whether prescribed or ad libitum rehydration with a $\mathrm{CHO}-\mathrm{E}$ solution, during $4 \mathrm{~h}$ recovery from prolonged, submaximal running, influenced subsequent endurance capacity (Wong et al., 1998b). Seven well-trained athletes (mean \pm S.E.M.; age: $19.8 \pm 0.3$ years) performed the "recovery" protocol on two occasions, at least 7 days apart. During the REC, the runners were allowed to drink a CHO-E solution (6. 9\% Lucozade-Sport; Sodium: $24 \mathrm{mmol}^{-1}$; Potassium: $2.6 \mathrm{mmol}$ $\mathrm{1}^{-1}$; Calcium: $1.2 \mathrm{mmol}^{-1}$; Osmolality: $300 \mathrm{mOsm}^{-1}$ ) ad libitum (AL) on one occasion. On the other occasion, the volume of the same fluid was prescribed (PI) from calculations of the body mass lost during T1. The prescribed intake was ingested 15 min after and at each hour after T1 during the REC. Subjects drank $725 \mathrm{ml}$ of the $\mathrm{CHO}$-E solution as their first prescribed intake in order to consume $50 \mathrm{~g}$ of CHO (Coyle, 1993). This volume of fluid was subtracted from the total volume prescribed so as to calculate hourly fluid intake.

After exercising for $90 \mathrm{~min}$ in T1, the subjects lost 2 . $6 \pm 0.2 \%$ and $2.5 \pm 0.3 \%$ of their initial body mass in the PI trial and the AL trial, respectively (NS). At the end of the REC in both trials, the subjects had not restored their body mass to pre-T1 values. This was in spite of the fact that in the PI trial, the CHO-E solution ingested was calculated to replace the total fluid loss during T1. All subjects completed the 90 min run during $\mathrm{T} 1$ on both trials. However, during T2, in the PI trial, the exercise time to exhaustion was $16 \%$ longer ( $\mathrm{p}$ $<0.05$ ) than during T2 in the AL trial (PI: $69.9 \pm 9.1 \mathrm{vs}$. AL: $60.2 \pm 10.2 \mathrm{~min}$ ). Although there was no difference between conditions in the total volume ingested (PI: $1499 \pm 155$ vs. AL: $1405 \pm 215 \mathrm{ml}$ ), the volume of CHO-E solution ingested in the fourth hour of the REC was greater in the PI trial than in the AL trial (PI: $258 \pm 52$ vs. AL: $78 \pm 34 \mathrm{ml} ; \mathrm{p}<0$. 05). The amount of glucose ingested in this period during the PI trial was also greater than during the AL trial (PI: $17.8 \pm$ 3.6 vs. AL: $5.4 \pm 2.4 \mathrm{~g} ; \mathrm{p}<0.05$ ) (Table 1). There was a higher blood lactate concentration at the start of T2 in the PI trial compared with the value for T2 in the AL trial (PI: 1. $12 \pm 0.20$ vs. AL: $0.94 \pm 0.09 \mathrm{mmol}^{-1} ; \mathrm{p}<0.05$ ), but there were no differences in blood glucose, plasma insulin, free fatty acid concentrations (Table 2) and urine volume between trials. The results of this study suggest that drinking a prescribed volume of CHO-E solution after prolonged exercise, calculated to replace the body fluid losses, restores endurance capacity to a greater extent than ad libitum rehydration during $4 \mathrm{~h}$ of recovery, even though the total volumes ingested were the same between trials.
One of the notable findings of the present study was that there was no difference in the total volume ingested between the two trials. Following the rehydration period in the PI and AL trials, the subjects remained hypohydrated and the volume of fluid retained expressed as a percentage of the volume ingested (\% rehydration) was $53.6 \pm 7.6 \%$ and $42.7 \pm 7.6 \%$, respectively. This amount of rehydration is less than the values reported by other researchers using prescribed (controlled) (Costill and Sparks, 1973; Nielsen et al., 1986; Gonzalez-Alonso et al., 1992; Lambert et al., 1992) and ad libitum rehydration protocols (Nose et al., 1988). By employing prescribed rehydration after exercise-induced or thermal dehydration, which decreased body mass by 2.5 4.1\%, Costill and Sparks (1973), Gonzalez-Alonso et al. (1992) and Lambert et al. (1992) also found that subjects were hypohydrated after ingestion of a fluid equal to their weight loss. Carter and Gisolfi (1989) found that $3 \mathrm{~h}$ of ad libitum drinking was inadequate to completely rehydrate their subjects following prolonged exercise. The dissimilarities in degree of dehydration and percentage rehydration between the present study reported and those studies in the literature may be due to the utilisation of different experimental protocols and rehydration solutions. Even though the approaches to the question of how best to rehydrate after exercise are different, there appears to be agreement that complete rehydration does not occur during recovery period of only 3 to $6 \mathrm{~h}$ when the volume of fluid ingested is equivalent to the weight loss during exercise.

\section{Effects of the Amount of Carbohydrate on Recovery}

For rapid replenishment of the body's limited CHO stores, it has been suggested that at least $50 \mathrm{~g}$ of $\mathrm{CHO}$ should be ingested immediately after exercise in order to hasten the glycogen resynthesis process (Coyle, 1993). However, it is unclear whether consuming only $50 \mathrm{~g}$ of $\mathrm{CHO}$ immediately after exercise is sufficient for restoring endurance capacity for subsequent exercise. Theoretically, this is unlikely because providing a greater amount of $\mathrm{CHO}$ after prolonged exercise is believed to be more beneficial in replenishing the body's glycogen stores and, thus, further enhancing the subsequent endurance capacity. Therefore, a study was designed to examine the influence of ingesting $50 \mathrm{~g}$ of CHO immediately after exercise, either with subsequent serial $\mathrm{CHO}$ feeding or water ingestion during the REC from prolonged, submaximal running, on rehydration and subsequent exercise capacity (Wong et al., 1996a).

Eight male subjects (age: $31.4 \pm 2.6$ years) performed the "recovery" protocol [i.e. $90 \mathrm{~min}$ run at $70 \% \mathrm{VO}_{2} \max (\mathrm{T} 1)$, $4 \mathrm{~h}$ rehydration-recovery (REC), and open-ended run at $70 \%$ $\left.\mathrm{VO}_{2} \max (\mathrm{T} 2)\right]$ on two occasions. During the REC, subjects ingested a prescribed volume of fluid equal to the body mass 
lost ( $2.7 \%$ of pre-exercise body mass) during $\mathrm{T} 1$ in both conditions. Subjects ingested $50 \mathrm{~g}$ of $\mathrm{CHO}$ from a $6.9 \%$ CHO-E solution (Sodium: $24 \mathrm{mmol}^{-1}$; Potassium: $2.6 \mathrm{mmol}^{-1}$; Calcium: $1.2 \mathrm{mmol}$ $\mathrm{l}^{-1}$; Osmolality: $305 \mathrm{mOsm.l}^{-1}$ ) $15 \mathrm{~min}$ after T1 on both occasions as their first prescribed fluid intake. Thereafter, subjects drank either the same solution (CE) or water (W) at each hour after T1 during the REC. During T2, the run time to exhaustion was $54.2 \pm 9.2 \mathrm{~min}$ in the CE trial and $52.2 \pm 6.2 \mathrm{~min}$ in the W trial, respectively (NS). There was no difference between trials in the total volume of fluid ingested (CE: $2157 \pm 255$ $\mathrm{ml}$; CW: $1950 \pm 90 \mathrm{ml}$ ). However, the percent rehydration during the $\mathrm{CE}$ trial was greater than that of $\mathrm{CW}$ trial (CE: $73.5 \pm$ $4.2 \%$ vs. CW: $63.0 \pm 5.7 \% ; \mathrm{p}<0.05$ ) (Figure 2). Higher blood glucose $(p<0.01)$ and serum insulin concentration $(p<0$. $01)$, but lower plasma FFA concentration $(p<0.01)$ were observed throughout the REC in the CE trial compared with the $\mathrm{CW}$ trial. Blood glucose and serum insulin were not different between trials during T2. Serial CHO feeding during the REC was associated with increased $\mathrm{CHO}$ oxidation and suppressed fat oxidation during subsequent exercise. Thus, ingesting approximately $150 \mathrm{~g}$ of $\mathrm{CHO}$ in the form of a $6.9 \%$ CHO-electrolyte solution over a $4 \mathrm{~h}$ recovery period following prolonged running is more effective for rehydration compared to the same volume of fluid containing only $50 \mathrm{~g}$ of $\mathrm{CHO}$ and water, but does not have a greater effect on subsequent endurance capacity.

Although there is a greater variety of sports drinks currently available than has been the case in the past, some athletes still prefer water to these beverages. Thus, the contribution of the present study is to suggest that ingesting $50 \mathrm{~g}$ of $\mathrm{CHO}$ immediately after prolonged exercise followed by only water may be equally effective for the restoration of energy capacity as compared with ingesting $150 \mathrm{~g}$ of $\mathrm{CHO}$ in the form of sports drinks during such a $4 \mathrm{~h}$ recovery period. However, the results also demonstrate the efficacy of drinking a CHO-E solution on rehydration during a short-term recovery when compared to ingesting only water. Nevertheless, all subjects remained hypohydrated at the end of the REC in both conditions, despite the fluid ingested being equal to the weight loss during $\mathrm{T} 1$.

\section{Effects of Carbohydrate Ingestion and Rehydration per se on Recovery}

Despite fluids with different composition combined with a controlled drinking pattern have been employed for rapid fluid replacement after exercise-induced dehydration, complete rehydration is still not achieved during a short recovery period of only 2 to $6 \mathrm{~h}$, when the volume of fluid ingested is equal to the body mass loss (Costill \& Sparks, 1973; Gonzalez-Alonso et al., 1992; Carter \& Gisolfi, 1989; Nielsen et al., 1986; Maughan et al., 1994; Wong et al., 1998b).
In order to restore the body's fluid balance as rapidly as possible after dehydration, it has been suggested that ingestion of a larger fluid volume may be necessary during a short rehydration period (Grandjean et al., 1992). This notion has subsequently been examined and the research findings showed that complete rehydration could occur during a short rehydration period after exercise-induced dehydration when the volume ingested was substantially greater than the fluid loss during exercise (Maughan et al., 1994). In that study, the subjects drank a volume of fluid with a high sodium $\left(\mathrm{Na}^{+}\right)$concentration $\left(61 \mathrm{mmoll}^{-1}\right)$ equal to $200 \%$ of their body mass loss and positive fluid balance $(+427 \mathrm{ml}$ ) was reported at the end of the $6 \mathrm{~h}$ study period.

Although more effective rehydration could occur with a solution containing a higher $\mathrm{Na}^{+}$content (Maughan and Leiper, 1995; Shirreffs et al., 1996) and/or low concentration of CHO (Maughan et al., 1996), the effects of ingesting such a large volume of fluid on subsequent exercise performance have not been addressed and little studies, if any, have been conducted to examine this issue. If ingestion of a large volume of fluid during a relatively short, controlled rehydration period restores hydration status to pre-exercise level, the question arises as to the consequences during subsequent exercise if $\mathrm{CHO}$ is included in the fluid. Therefore, a further study was undertaken to examine the effects of rehydration per se and $\mathrm{CHO}$ ingestion, during $4 \mathrm{~h}$ recovery, on subsequent endurance running capacity (Wong et al., 1996b).

Nine male subjects (age: $26.4 \pm 1.7$ years) performed the "recovery" protocol on two occasions. During the REC, subjects drank either a $6.9 \%$ CHO-E (CE) solution or a CHO-free sweetened placebo (PL) every $30 \mathrm{~min}$ after $\mathrm{T} 1 \mathrm{up}$ to the beginning of the $4 \mathrm{~h}$ of the REC. Volumes prescribed $(\mathrm{ml})$ were equal to $200 \%$ of the body mass lost during T1. However, the total volume of fluid ingested during the REC was only $170.8 \pm 12.6 \%$ and $172.6 \pm 13.8 \%$ of the body mass lost after T1 (NS). During $\mathrm{T} 2$, run time was $24.3 \pm 4.4 \mathrm{~min}$ longer in the CE trial (69. $3 \pm 5.5$ vs. $45.0 \pm 4.2 \mathrm{~min} ; \mathrm{p}<0.05$ ). After the REC, subjects were in positive fluid balance by $423 \pm 215 \mathrm{ml}$ in the $\mathrm{CE}$ trial and $446 \pm 239 \mathrm{ml}$ in the PL trial (NS) (Table 3). Higher blood glucose was observed throughout REC in the CE trial (Figure 3). Thus, these results suggest that positive fluid balance after prolonged running can be achieved by ingesting a prescribed volume of either a $6.9 \% \mathrm{CHO}-\mathrm{E}$ solution or a $\mathrm{CHO}$-free sweetened placebo during a $4 \mathrm{~h}$ recovery period, calculated to replace $\sim 170 \%$ of the body fluid loss. Nevertheless, ingesting a CHO-E solution is more effective in restoring endurance capacity compared to the same volume of placebo solution.

It is well documented that performance during prolonged exercise is limited by a reduction, if not depletion, of the limited 
glycogen stores in the working muscles (Ahlborg et al., 1967; Costill et al., 1988; Tsintzas et al., 1995), and this may be compounded by dehydration. In the present study, since subjects had a similar hydration status after the REC in both conditions, the differences in performance during $\mathrm{T} 2$ between the $\mathrm{CE}$ and PL trials can not be attributed to any difference in the degree of hydration level. Thus, it is reasonable to conclude that it was the provision of additional $\mathrm{CHO}$ which enabled the subjects to run longer during $\mathrm{T} 2$.

This improvement in subsequent endurance capacity following the ingestion of a CHO-E solution during short-term recovery confirmed the findings of Fallowfield et al. (1995). In that study, subjects ingested either $1.0 \mathrm{gCHO}^{-1}{ }^{-1}$ body mass immediately after a $90 \mathrm{~min}$ run and then $2 \mathrm{hr}$ later, or an equal volume of a placebo solution at the same time points over a $4 \mathrm{hr}$ recovery period. Although their subjects were still hypohydrated before the second run in both conditions, they ran 22 min longer in the CHO trial. In the present study, subjects were in positive fluid balance in both trials after consuming approximately $170 \%$ of their body mass loss in T1. Despite the similar hydration levels, all nine subjects were able to run longer during T2 in the $\mathrm{CE}$ trial and the run time to exhaustion was $24.3 \pm 4$. 4 min longer when compared with the PL trial. The difference in the amount of $\mathrm{CHO}$ ingested between the previous study and the present one was about $109 \mathrm{~g}$. However, there is only $\sim 2$ min difference in the average run time to exhaustion between these two studies. Thus, it seems that excess $\mathrm{CHO}$ ingestion may not further improve the subsequent endurance capacity 4 hr later. This suggestion is supported by the results of another similar study in which no differences were observed in run time during the subsequent exercise between the ingestion of 1.0 and $3.0 \mathrm{~g} \mathrm{CHO} \mathrm{kg}^{-1}$ body mass $2 \mathrm{~h}^{-1}$ (Fallowfield \& Williams, 1997).

Because of the high volume of fluid ingested over the REC, all subjects complained about the GI discomfort during T2 in both trials. It appears that post-exercise rehydration with continued fluid and $\mathrm{CHO}$ ingestion needs to be carefully monitored in terms of GI responses if the recovery period between the bouts of exercise is relatively short. In this study, although subjects achieved euhydration with both drinks after the REC, the reported GI distress during subsequent exercise indicates the practical constraints of ingesting such a large volume of fluid within a short period.

In order to examine, and verify, the effects of ingesting different amounts of $\mathrm{CHO}$ in the form of a CHO-E solution during the REC on rehydration and subsequent endurance capacity, a further study was undertaken using the same experimental procedures (Wong et al., 1998a) as described previously. Nine male subjects (age: $34.3 \pm 2.4$ years) performed the "recovery" protocol on two occasions. During the REC, a fixed volume of fluid equivalent to $150 \%$ of the body mass lost during T1 was consumed. Subjects ingested $50 \mathrm{~g}$ of $\mathrm{CHO}$ from a $6.5 \%$ CHO-E solution $30 \mathrm{~min}$ after $\mathrm{T} 1$ on both occasions as their first prescribed fluid intake. Thereafter, subjects ingested either the same solution (CE) or a CHO-free sweetened placebo (PL) every $30 \mathrm{~min}$ up to the beginning of the $4 \mathrm{~h}$ of the REC. During T2, the run times were $56.9 \pm 8.1 \mathrm{~min}$ in the $\mathrm{CE}$ trial and $65.4 \pm 7.8 \mathrm{~min}$ in the PL trial (NS). After the REC, the subjects were almost equally euhydrated (CE: $0 \pm 184 \mathrm{ml}$; PL: $-27 \pm 120 \mathrm{ml}$ ) in both conditions (NS). Serial CHO feeding over the REC was accompanied by enhanced CHO oxidation and suppressed fat oxidation (Figure 4). These results suggest that ingesting a placebo containing $50 \mathrm{~g}$ of $\mathrm{CHO}$ and placebo over a $4 \mathrm{~h}$ period following prolonged running, calculated to replace $150 \%$ of the body fluid loss, is equally effective in achieving approximate euhydration and restoring endurance capacity compared to the same volume of CHO-E solution containing $\sim 167 \mathrm{~g}$ of $\mathrm{CHO}$.

\section{Conclusions}

Despite the vast body of published data addressing the effectiveness of different rehydration fluids after exercise-induced dehydration and the rate of muscle glycogen resynthesis over various time periods, there are surprisingly few published studies which have investigated whether the restoration of exercise capacity parallels the replenishment of body fluid and $\mathrm{CHO}$ stores. Therefore, based on previous research findings, a standardised "recovery" protocol was used throughout the studies reported in this paper in order to examine the influence of rehydration on subsequent exercise capacity. These studies have provided evidence to support the suggestion that sufficient fluid replacement following exerciseinduced dehydration maintains cardiovascular function and thermal balance during subsequent exercise. Thus, rapid restoration of the body's fluid balance plays an important role during postexercise recovery. In order to achieve euhydration during recovery, a volume of fluid substantially larger (150\%) than that lost must be ingested. The provision of additional $\mathrm{CHO}(\sim 150$ to 170 g) would be expected to restore the body's $\mathrm{CHO}$ stores to a greater extent than a smaller amount of $\mathrm{CHO}(50 \mathrm{~g})$ during the REC, and thereby, improve the subsequent endurance capacity. However, this was not the case. It appears that the ingestion of large amounts of CHO, during the REC, may have resulted in metabolic disturbances in the fat and $\mathrm{CHO}$ substrate provision which prevented an improvement in subsequent endurance capacity during T2. Further research is needed to elucidate how to limit the metabolic disturbances and hormonal changes induced by different rehydration regimens during the short-term recovery and subsequent exercise. The role of muscle glycogen during the subsequent prolonged exercise in combination with different levels of rehydration also warrants further investigation. 


\section{References}

Ahlborg, B., Bergstrom, J., Brohult, J., Ekelund, L-G., Hultman, E., \& Maschio, G. (1967). Human muscle glycogen content and capacity for prolonged exercise after different diets. Forsvarsmedicin., 3, 85-99.

Armstrong, L.E., Costill, D.L., \& Fink, W.J. (1985). Influence of diuretic-induced dehydration on competitive running performance. Med. Sci. Sports Exerc., 17, 456-461.

Below, P.R., Mora-Rodriguez, R., Gonzalez-Alonso, J., \& Coyle, E.F. (1995). Fluid and carbohydrate ingestion independently improve performance during $1 \mathrm{~h}$ of intense exercise. Med. Sci. Sports Exerc., 27, 200-210.

Bergstrom, J., Hermansen, L., Hultman. E., \& Saltin. B. (1967). Diet, muscle glycogen and physical performance. Acta Physiol. Scand., 71, 140-150.

Bergstrom, J., \& Hultman, E. (1967). A study of the glycogen metabolism during exercise in man. Scand. J. Clin. Lab. Invest., 19, 218-228.

Carter, J.E., \& Gisolfi, C.V. (1989). Fluid replacement during and after exercise in the heat. Med. Sci. Sports Exerc., 21, 532-539.

Christensen, E.H,. \& Hansen, O. (1939a). Arbeitsfahigkeit und ernahrung. Skand. Arch. Physiol., 81, 160-171.

Christensen, E.H., \& Hansen, O. (1939b). Hypoglykamie, arbeitsfahigkeit und ermudung. Skand. Arch. Physiol., 81, 172-179.

Costill, D.L. (1988). Carbohydrates for exercise: dietary demands for optimal performance. Int. J. Sports Med., 9, 1-18.

Costill, D.L., Flynn, M.G., Kirwan, J.P., Houmard, J.A., Mitchell, J.B., Thomas, R., \& Park, N. (1988). Effects of repeated days of intensified training on muscle glycogen and swimming performance. Med. Sci. Sports Exerc., 20, 249-254.

Costill, D.L., \& Sparks, K.E. (1973). Rapid fluid replacement following thermal dehydration. J. Appl. Physiol., 34, 299. 303.

Coyle, E.F. (1993). Carbohydrate supplement: why, when, what and how much? Insider, 1, 1.
Coyle, E.F., \& Montain, J. (1992). Benefits of fluid replacement with carbohydrate during exercise. Med. Sci. Sports Exerc., 24, S324-S330.

Fallowfield, J.L., \& Williams, C. (1997). The influence of a high carbohydrate intake during recovery from prolonged, constant pace running. Int. J. Sports Nutr. 7, 10-25.

Fallowfield, J.L., Williams, C., \& Singh, R. (1995). The influence of ingesting a carbohydrate-electrolyte beverage during 4 hours of recovery on subsequent endurance capacity. Int. J. Sports Nutr., 5, 285-299.

Gonzalez-Alonso, J., Heaps, C.L., \& Coyle, E.F. (1992). Rehydration after exercise with common beverages and water. Int. J. Sports Med., 13, 399-406.

Grandjean, P.W., Cassiday, A.P., Cole, K.J., \& Mitchell, J.B. (1992). Fluid volume effects on rehydration and body fluid balance following exercise induced dehydration. Med. Sci. Sports Exerc., 24, S155.

Greenleaf, J.E., \& Sargent II, F. (1965). Voluntary dehydration in man. J. Appl. Physiol., 20, 719-724.

Heaps, C.L., Gonzalez-Alonso, J., \& Coyle, E.F. (1994). Hypohydration causes cardiovascular drift without reducing blood volume. Int. J. Sports Med., 15, 74-79.

Hermansen, L., Hultman, E., \& Saltin, B. (1967). Muscle glycogen during prolonged severe exercise. Acta Physiol. Scand., 71, 129-139.

Ivy, J.L., Katz, A.L., Cutler, C.L., Sherman, W.M., \& Coyle, E.F. (1988a). Muscle glycogen synthesis after exercise: effect of time of carbohydrate ingestion. J. Appl. Physiol., 64, 1480-1485.

Ivy, J.L., Lee, M.C., Brozinick, J.T., \& Reed, M.J. (1988b). Muscle glycogen storage after different amounts of carbohydrate ingestion. J. Appl. Physiol., 65, 2018-2023.

Keizer, H.A., Kuipers, H., van Kranenburg, G., \& Geurten, P. (1987). Influence of liquid and solid meals on muscle glycogen resynthesis, plasma fuel hormone response, and maximal physical work capacity. Int. J. Sports Med., 8:, 99-104.

Lambert, C.P., Costill, D.L., McConell, G.K., Benedict, M.A., Robergs, G.P., \& Fink, W.J. (1992). Fluid replacement after dehydration: influence of beverage carbonation and carbohydrate content. Int. J. Sports Med., 13, 285-292. 
Maughan, R.J., \& Leiper, J.B. (1995). Sodium intake and postexercise rehydration in man. Eur. J. Appl. Physiol., 71, 311-319.

Maughan, R.J., Leiper, J.B., \& Shirreffs, S.M. (1996). Restoration of fluid balance after exercise-induced dehydration: effects of food and fluid intake. Eur. J. Appl. Physiol., 73, 317325 .

Maughan, R. J., Owen, J.H., Shirreffs, S.M., \& Leiper, J.B. (1994.) Post-exercise rehydration in man: effects of electrolyte addition to ingested fluids. Eur. J. Appl. Physiol., 69, 209-215.

Montain, S.J., \& Coyle, E.F. (1992a). Fluid ingestion during exercise increases skin blood flow independent of increases in blood volume. J. Appl. Physiol., 73, 903-910.

Montain, S.J., \& Coyle, E.F. (1992b). Influence of graded dehydration on hyperthermia and cardiovascular drift during exercise. J. Appl. Physiol., 73, 1340-1350.

Montain, S.J., Sawka, M.N., Latzka, W.A., \& Valeri, C.R. (1998). Thermal and cardiovascular strain from hypohydration: influence of exercise intensity. Int. J. Sports Med., 19, 8791.

Nadel, E.R., Fortney, S.M., \& Wenger, C.B. (1980). Effect of hydration state on circulatory and thermal regulation. $J$. Appl. Physiol., 49, 715-721.

Neufer, P.D., Sawka, M.N., Young, A.J., Quigley, M.D., Latzka, W.A., \& Levine, L. (1991). Hypohydration does not impair skeletal muscle glycogen resynthesis after exercise. J. Appl. Physiol., 70, 1490-1494.

Nielsen, B., Sjogaard, G., Ugelvig, J., Knudsen, B., \& Dohlmann, B. (1986). Fluid balance in exercise dehydration and rehydration with different glucose-electrolyte drinks. Eur. J. Appl. Physiol., 55, 318-325.

Noakes, T.D., Adams, B.A., Myburgh, K.H., Greeff, C., Lotz, T., \& Nathan, M. (1988). The danger of an inadequate water intake during prolonged exercise. Eur. J. Appl. Physiol., 57: $210-219$.
Nose, H., Mack, G.W., Shi X., \& Nadel, E.R. (1988). Role of osmolality and plasma volume during rehydration in humans. J. Appl. Physiol., 65, 325-331.

Shirreffs, S.M., Taylor, A.J., Leiper, J.B., \& Maughan, R.J. (1996). Post-exercise rehydration in man: effects of volume consumed and sodium content of ingested fluids. Med. Sci. Sports Exerc. 28, 1260-71.

Tsintzas, O-K., Williams, C., Boobis, L., \& Greenhaff, P. (1995). Carbohydrate ingestion and glycogen utilization in different muscle fibre types in man. J. Physiol., 489, 243-250.

Tsintzas, O-K., Williams, C., Boobis, L., \& Greenhaff, P. (1996). Carbohydrate ingestion and single muscle fiber glycogen metabolism during prolonged running in men. J. Appl. Physiol., 81, 801-809.

Walsh, R.M., Noakes, T.D., Hawley, J.A., \& Dennis, S.C. (1994). Impaired high-intensity cycling performance time at low levels of dehydration. Int. J. Sports Med., 15, 392-398.

Williams, C. (1993). Carbohydrate needs of elite athletes. In: Simopoulos, A.P. and Pavlou, K.N. (eds.) World Review of Nutrition and Dietetics, Vol. 71: Nutrition and Fitness for Athletes. Basel: Karger, pp. 34-60.

Wong, S.H., Chu, Y.M., Lee K.C., \& Williams, C. (1996a). Influence of rehydration with a carbohydrate solution and water during $4 \mathrm{~h}$ recovery from prolonged submaximal running on subsequent exercise capacity. J. Sports Sci., 14, 104.

Wong, S.H., Williams, C., \& Adams, N. (1996b). Effect of a high volume of carbohydrate solution on rehydration during recovery from prolonged running and subsequent exercise capacity. J. Sports Sci., 14, 351.

Wong, S.H., Williams, C., \& Hazir, T. (1998a). Effects of different amounts of carbohydrate ingestion on subsequent endurance capacity and rehydration during recovery. Med. Sci. Sports Exerc. 30, S245.

Wong, S.H., Williams, C., Simpson, M., \& Ogaki, T. (1998b). Influence of fluid intake pattern on short-term recovery from prolonged, submaximal running and subsequent exercise capacity. J. Sports Sci., 16, 143-152. 
Table 1. The Volume of CHO-electrolyte Solution (ml) and the Amount of Glucose (gram) per kg Body Weight Ingested during the REC in the PI and AL Trials.

\begin{tabular}{|c|c|c|c|c|}
\hline Time (h) & 1 & 2 & 3 & 4 \\
\hline \multirow{3}{*}{$\begin{array}{l}\text { Volume } \\
(\mathrm{ml})\end{array}$} & $\begin{array}{l}725 \\
(0)\end{array}$ & $\begin{array}{l}258 \\
(52)\end{array}$ & $\begin{array}{l}258 \\
(52)\end{array}$ & $\begin{array}{l}258^{\mathrm{a}} \\
(52)\end{array}$ \\
\hline & & & & \\
\hline & $\begin{array}{l}985 \\
(145)\end{array}$ & $\begin{array}{l}196 \\
(43)\end{array}$ & $\begin{array}{l}146 \\
(51)\end{array}$ & $\begin{array}{l}78 \\
(34)\end{array}$ \\
\hline \multirow{3}{*}{$\begin{array}{l}\text { Glucose } \\
\left(\mathrm{g} \cdot \mathrm{kg}^{-1}\right)\end{array}$} & $\begin{array}{c}0.87 \\
(0)\end{array}$ & $\begin{array}{l}0.30 \\
(0.05)\end{array}$ & $\begin{array}{l}0.30 \\
(0.05)\end{array}$ & $\begin{array}{r}0.30^{\mathrm{a}} \\
(0.05)\end{array}$ \\
\hline & & & & \\
\hline & $\begin{array}{l}1.16 \\
(0.15)\end{array}$ & $\begin{array}{c}0.23 \\
(0.05)\end{array}$ & $\begin{array}{l}0.17 \\
(0.06)\end{array}$ & $\begin{array}{c}0.10 \\
(0.04)\end{array}$ \\
\hline
\end{tabular}

Note. Values represent Means $( \pm \mathrm{SEM}) ;{ }^{a} \mathrm{p}<.05$, PI vs AL. 
Table 2. Blood Glucose, Serum Insulin, Blood Lactate, Plasma Free Fatty Acid Concentrations before and after T1 and T2 in the ad libitum and Prescribed Intake Trials.

\begin{tabular}{|c|c|c|c|c|c|}
\hline & Pre-T1 & Post-T1 & (4 h recovery) & Pre-T2 & Post-T2 \\
\hline \multicolumn{6}{|c|}{ Glucose (mmoll-1-1) } \\
\hline Ad libitum & $\begin{array}{c}4.4 \\
(0.3)\end{array}$ & $\begin{array}{c}4.6 \\
(0.3)\end{array}$ & & $\begin{array}{c}3.8 \\
(0.2)\end{array}$ & $\begin{array}{c}4.0 \\
(0.3)\end{array}$ \\
\hline Prescribed intake & $\begin{array}{c}4.5 \\
(0.1)\end{array}$ & $\begin{array}{c}4.6 \\
(0.2)\end{array}$ & & $\begin{array}{c}4.1 \\
(0.3)\end{array}$ & $\begin{array}{c}3.8 \\
(0.1)\end{array}$ \\
\hline \multicolumn{6}{|c|}{ Insulin $\left(\mathrm{m} U \cdot \mathrm{l}^{-1}\right)$} \\
\hline Ad libitum & $\begin{array}{c}6.1 \\
(1.4)\end{array}$ & $\begin{array}{c}6.0 \\
(0.6)\end{array}$ & & $\begin{array}{c}5.0 \\
(1.7)\end{array}$ & $\begin{array}{c}7.9 \\
(1.1)\end{array}$ \\
\hline Prescribed intake & $\begin{array}{c}5.8 \\
(0.9)\end{array}$ & $\begin{array}{c}5.7 \\
(1.0)\end{array}$ & & $\begin{array}{c}4.7 \\
(1.0)\end{array}$ & $\begin{array}{c}7.4 \\
(1.4)\end{array}$ \\
\hline \multicolumn{6}{|c|}{ Lactate $\left(\mathrm{mmol} \cdot \mathrm{l}^{-1}\right)$} \\
\hline Ad libitum & $\begin{array}{c}1.1 \\
(0.1)\end{array}$ & $\begin{array}{c}2.8 \\
(0.5)\end{array}$ & & $\begin{array}{c}0.9 \\
(0.1)\end{array}$ & $\begin{array}{c}2.4 \\
(0.6)\end{array}$ \\
\hline Prescribed intake & $\begin{array}{c}1.3 \\
(0.1)\end{array}$ & $\begin{array}{c}2.6 \\
(0.6)\end{array}$ & & $\begin{array}{c}1.1 \\
(0.1)\end{array}$ & $\begin{array}{c}2.1 \\
(0.8)\end{array}$ \\
\hline \multicolumn{6}{|c|}{ Free fatty acids (mmol-1-1) } \\
\hline Ad libitum & $\begin{array}{c}0.3 \\
(0.1)\end{array}$ & $\begin{array}{c}0.8 \\
(0.1)\end{array}$ & & $\begin{array}{c}1.0 \\
(0.2)\end{array}$ & $\begin{array}{c}0.8 \\
(0.1)\end{array}$ \\
\hline Prescribed intake & $\begin{array}{c}0.3 \\
(0.1)\end{array}$ & $\begin{array}{c}0.7 \\
(0.1)\end{array}$ & & $\begin{array}{c}0.6 \\
(0.2)\end{array}$ & $\begin{array}{c}0.9 \\
(0.1)\end{array}$ \\
\hline
\end{tabular}

Note. Values represent Means ( \pm SEM). 
Table 3. Body Fluid Balance after $\mathbb{T} 1$ and during $\mathbb{R E C}$ in the $\mathrm{CE}$ and $\mathrm{PL}$ Trials.

\begin{tabular}{lcc}
\hline & CE & PL \\
\hline Body mass after. T1 (\%) & $-3.0(0.1)$ & $-3.2(0.3)$ \\
Fluid prescribed during REC $(\mathrm{ml})$ & $4307(315)$ & $4600(531)$ \\
Fluid ingested during REC (ml) & $3582(234)$ & $3712(249)$ \\
Fluid ingested of volume prescribed $(\%)$ & $170.8(12.6)$ & $172.6(13.8)$ \\
Fluid balance after REC (ml) & $+423(215)$ & $+446(239)$ \\
\% Relhydration after REC & $123.7(10.6)$ & $125.3(10.0)$ \\
\hline
\end{tabular}

Note. Values represent Means ( \pm SEM).

$\underline{T 1}$

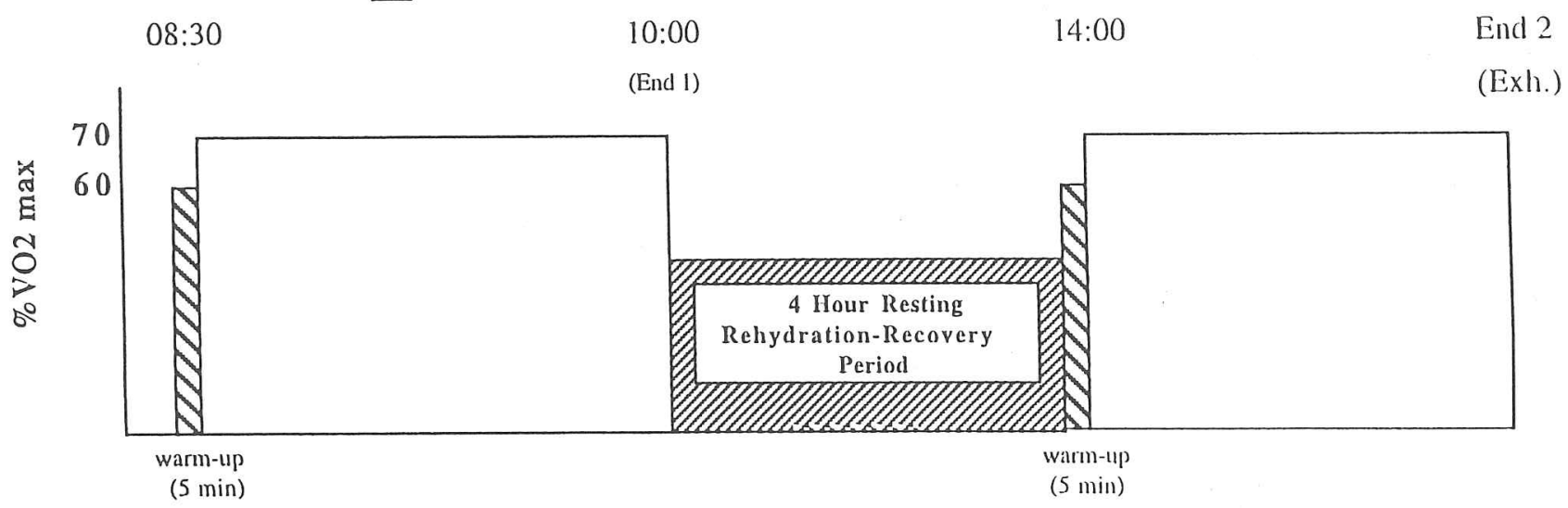

Figure 1. Schematic Representation of the Standard "Recovery" Experimental Model 


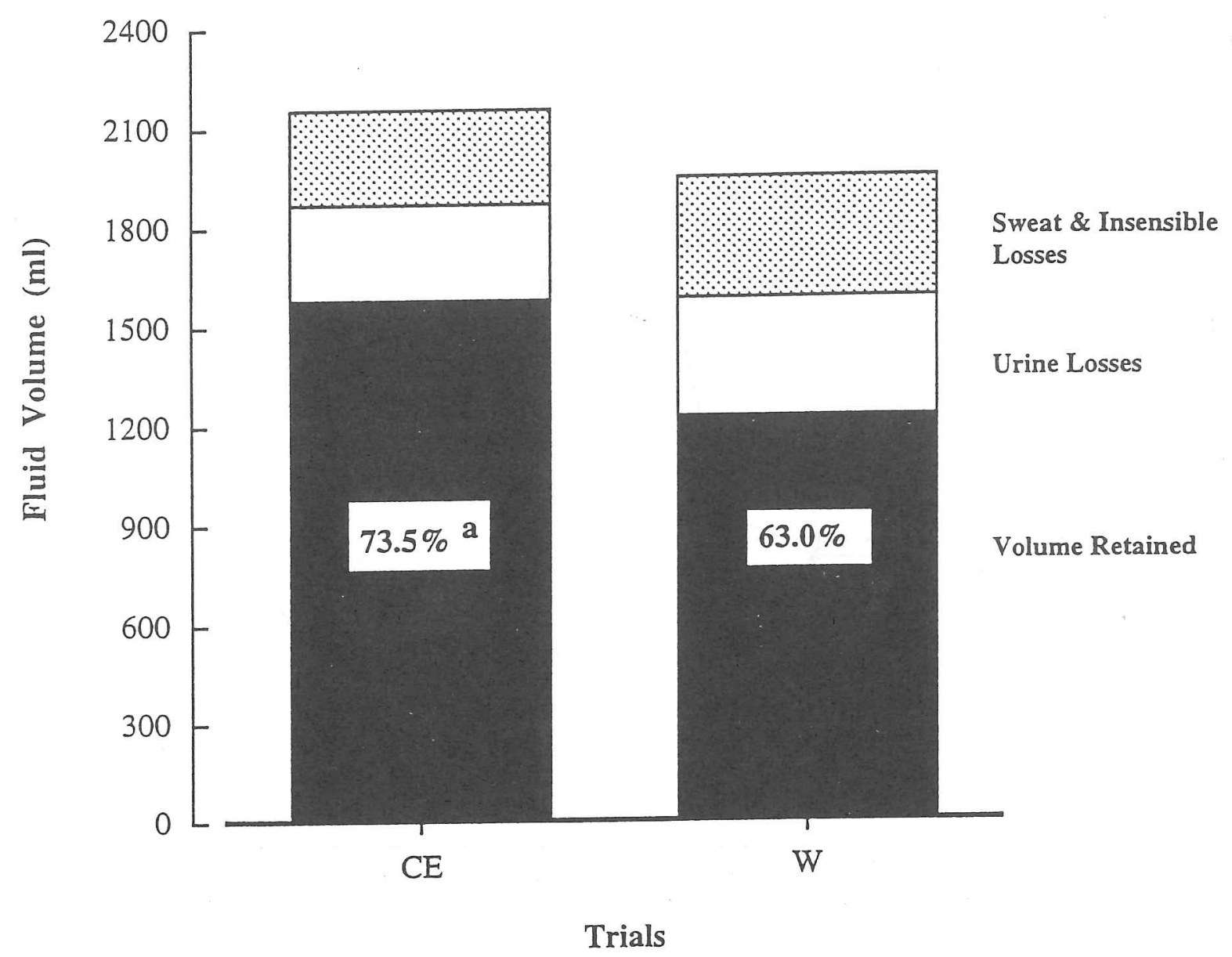

Figure 2. Fate of the Ingested Volume During the REC in the CE and W Trials. The Height of the Graph Represents the Total Amount of Fluid Consumed (ml). The Stacked Bars Represent the Fate of the Ingested Volume: The Ingested Fluid was either Retained in the Body or Lost in the Form of Urine and other Insensible Losses. The Percent of the Body Weight Loss that was Regained, Percent Rehydration, was used as Indicative of the Volume Retained.

$\mathrm{a}_{\mathrm{p}}<0.05, \mathrm{CE} v \mathrm{~s}$. W 


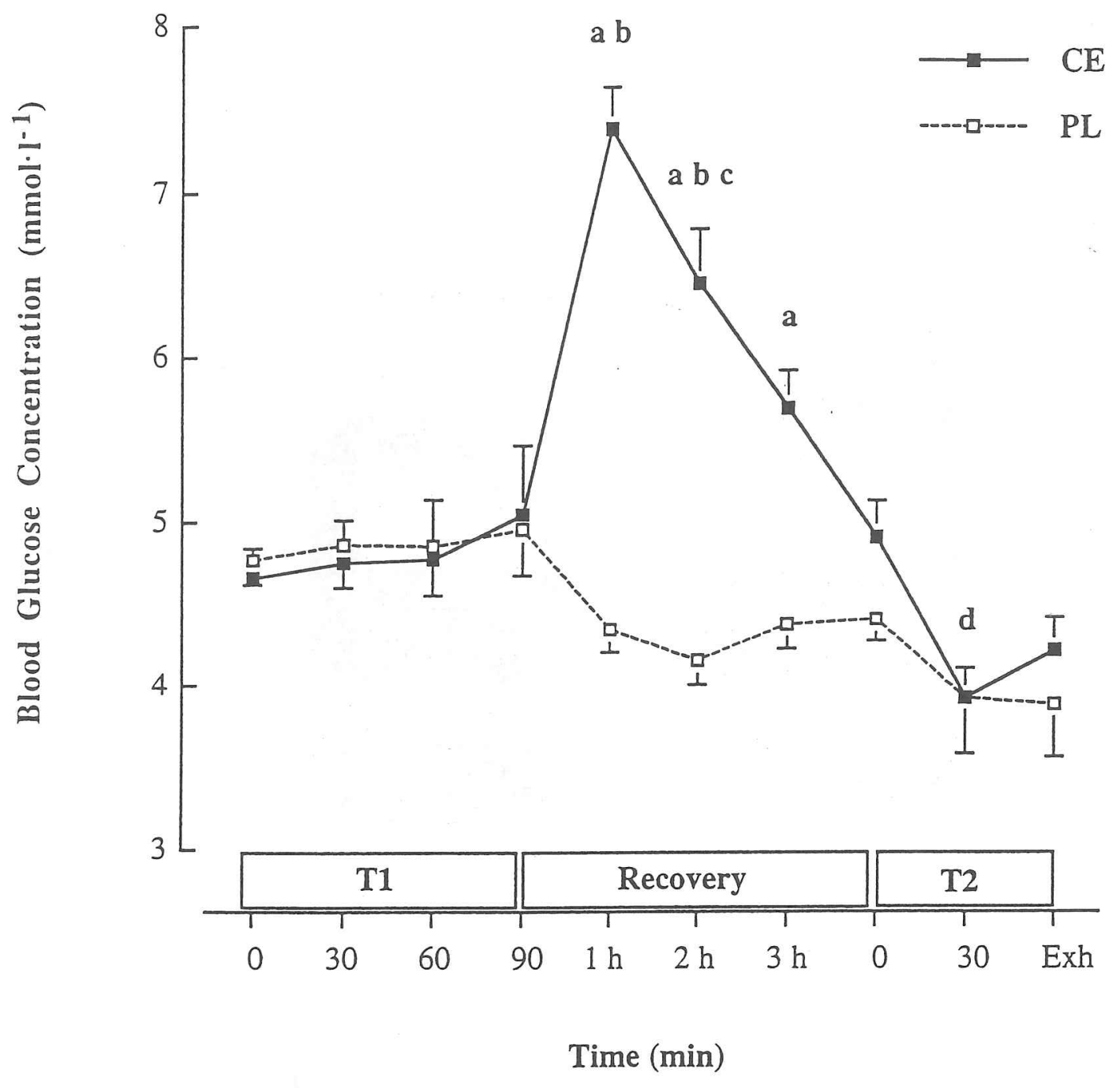

Figure 3. Blood Glucose (mmole $\left.\right|^{-1}$ ) Concentration during $\mathrm{T} 1, \mathrm{Recovery}$, and $\mathrm{T} 2$ in the Carbohydrate (CE) and Placebo (PL) Trials (meantSEM)

\footnotetext{
${ }^{\mathrm{a}} \mathrm{p}<0.01, \mathrm{CE}$ vs. PL

${ }^{b} \mathrm{p}<0.01$ from $90 \mathrm{~min}$ of $\mathrm{T} 1$

${ }^{c} \mathrm{p}<0.05$ from $1 \mathrm{~h}$

${ }^{d} p<0.05$ from 0 min of $T 2$ in CE trial
} 

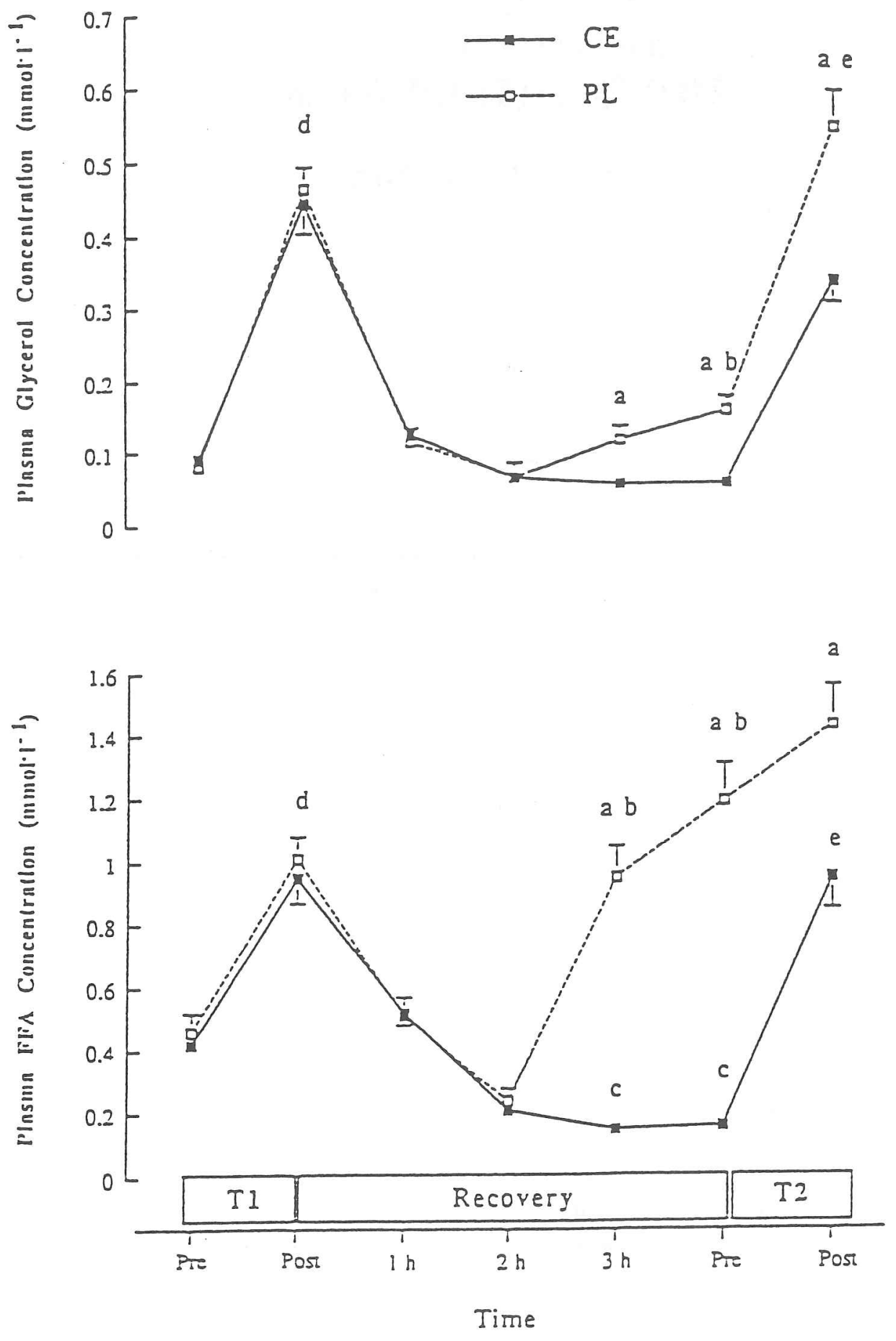

Figure 4. Plasma free fatty acid (mmold $\left.\mathrm{l}^{-1}\right)$ and plasma glycerol (mmold $\left.\mathrm{l}^{-1}\right)$ Concentration during T1, Recovery, and T2 in the Carbohydrate (CE) and Placebo (PL) Trials (meantsEM)

$$
\begin{aligned}
& { }^{a} p<0.05, \text { CE } v s . P L \\
& { }^{b} p<0.01 \text { from } 2 \mathrm{~h} \\
& { }^{c} p<0.05 \text { from } 1 \mathrm{~h} \\
& { }^{d} p<0.05 \text { from Pre T1 } \\
& { }^{\mathrm{e}} \mathrm{P}<0.01 \text { from Pre T2 }
\end{aligned}
$$

